\title{
Schönheit und Vielfalt der Palmen im Detail
}

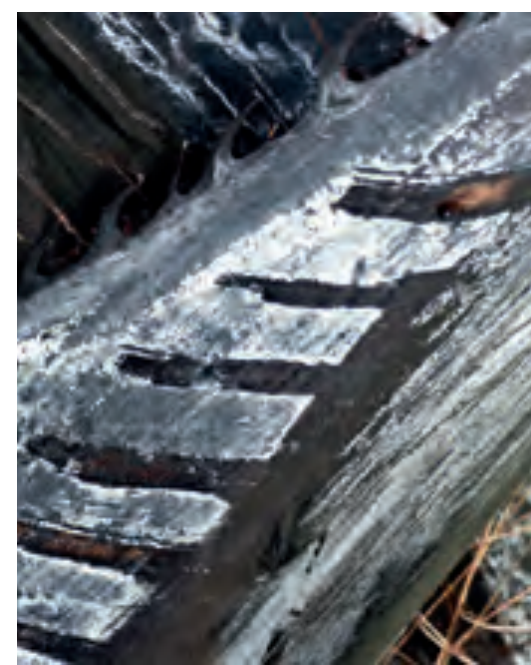

Abb. 1: Hyphaene thebaica.

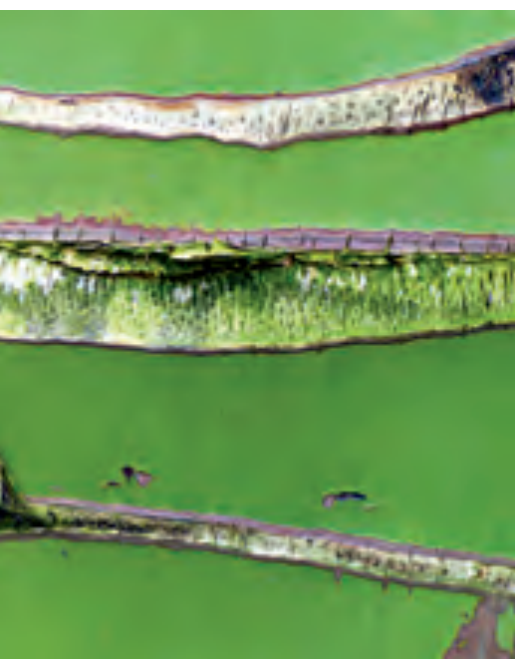

Abbb. 4: Cocos nucifera.

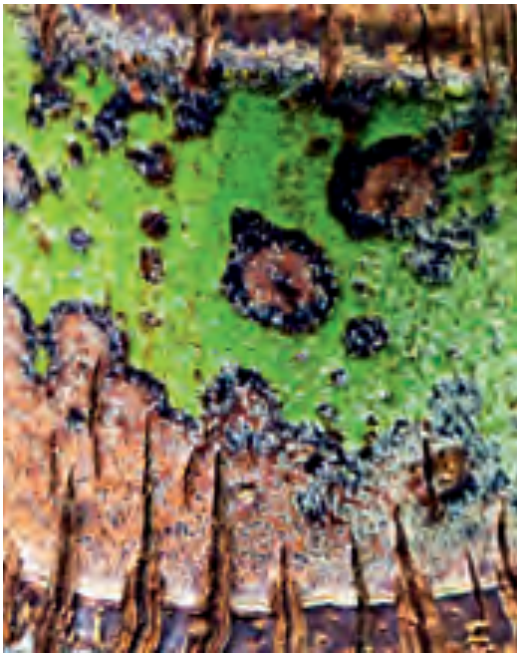

Abb. 7: Adonidia merrillii.

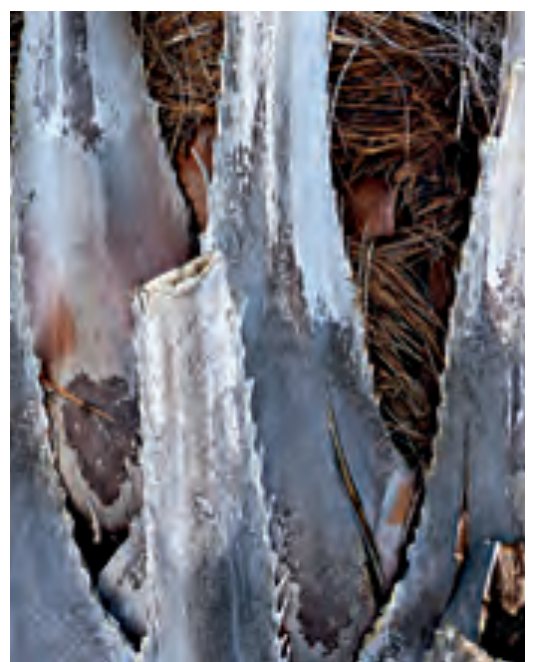

Abb. 2: Brahea armata.

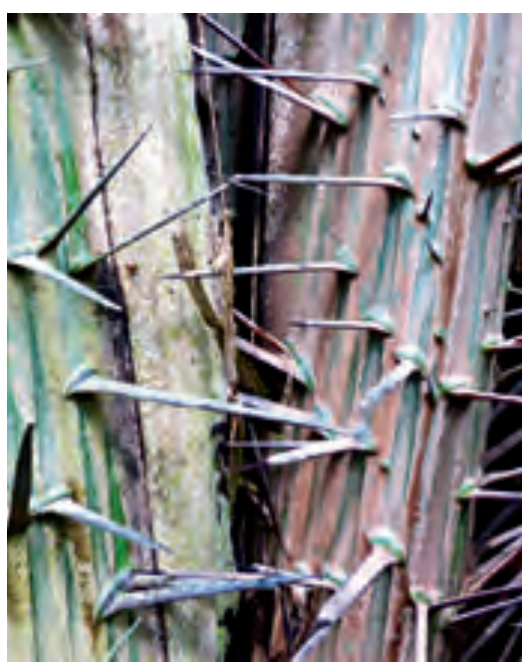

Abb. 5: Salacca zalacca.

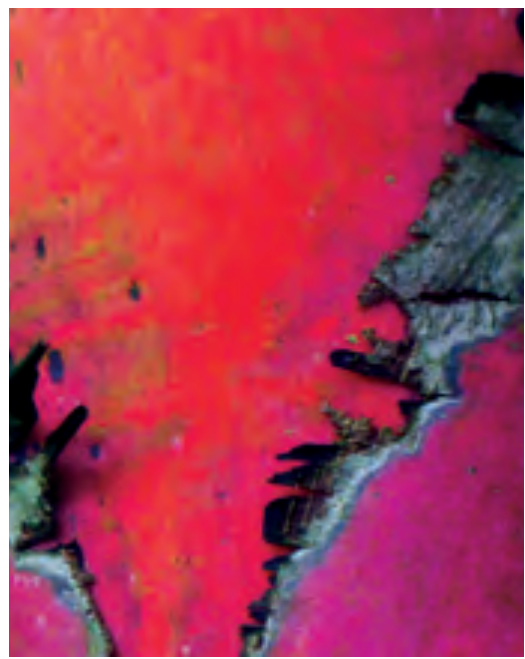

Abb. 8: Cyrtostachys renda.

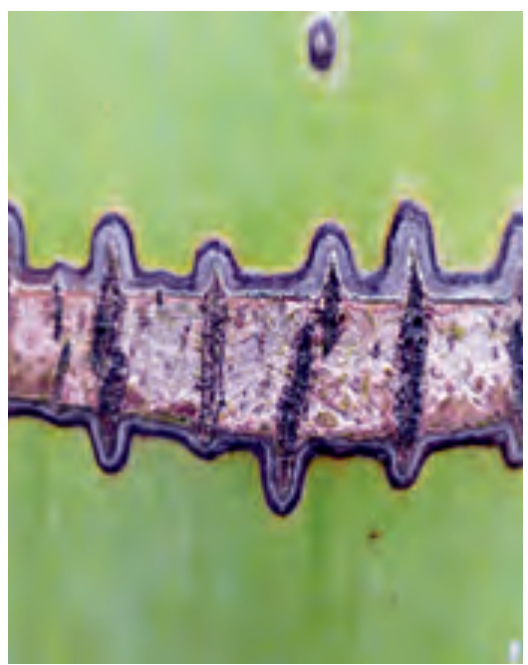

Abb. 3: Dypsis lutescens.

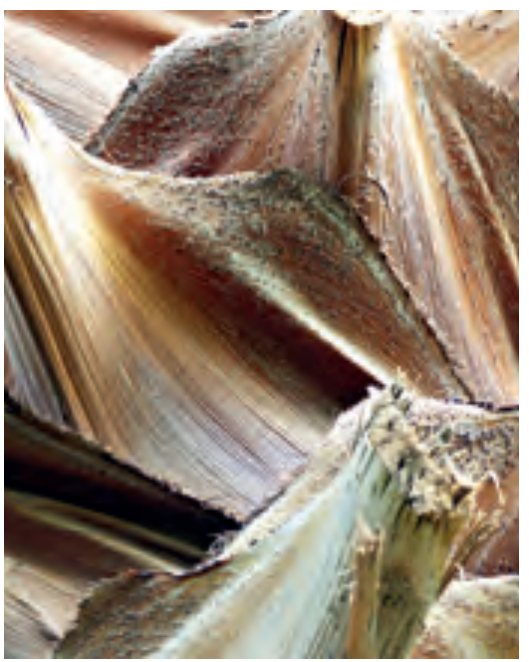

Abb. 6: Bismarckia nobilis.

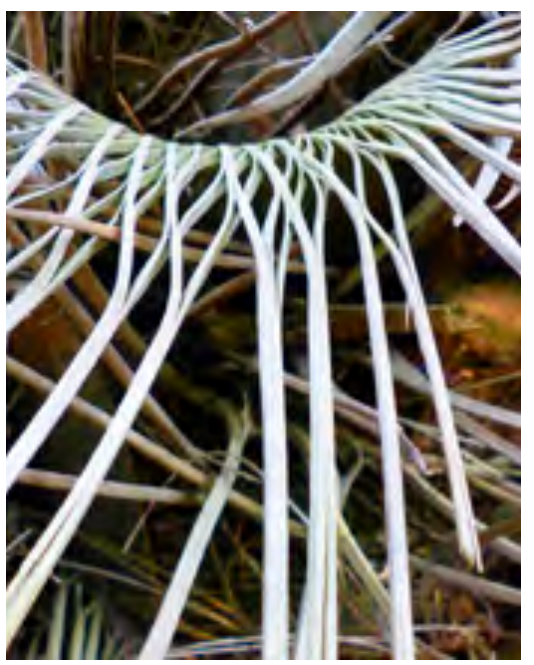

Abb. 9: Trithrinax acanthocoma. 